\title{
FIELD ASSISTED GLASS SEALING
}

\author{
GEORGE WALLIS \\ P. R. Mallory \& Co. Inc., Laboratory for Physical Science, Burlington, Ma 01803, U.S.A.
}

(Received March 20, 1974)

\begin{abstract}
The paper reviews the experimental, theoretical and applications work by several authors on a glass sealing technique which was announced five years ago. In the process, an electrostatic field is utilized to promote bonding at relatively low temperatures. The process variables and seal properties are described in detail. A discussion is presented of the mechanisms which are believed to play a role in bond formation. As an example of the utility of the technique, its highly successful application to the mounting of strain gauges is described.
\end{abstract}

\section{INTRODUCTION}

Five years ago, a new glass sealing technique ${ }^{1}$ was announced which has been variously known as "field assisted bonding", "anodic bonding" and "electrostatic sealing". Since then, several groups have worked on the process and a substantial number of papers has been published. This article is intended as a review of their work.

From the start, the new technique was felt to be unique in several important respects: (1) The surfaces remained solid during the sealing process; (2) no foreign materials such as adhesives or fluxes or solvents were utilized; and (3) the seals were made at relatively low temperatures. Among the resulting advantageous features are the following: since the glass remains solid during sealing, no macro-distortion takes place; if the glass acts as a structural member extremely close dimensional tolerances can be realized; if the glass has an optical function, an ability to make distortionless seals is of particular importance; in vacuum and in device applications it is a desirable feature that seals can be made without the use of fluxes or solvents which might give rise to contamination; the low sealing temperature broadens the area of application to devices whose characteristics deteriorate at higher temperatures. Thus, the new glass sealing technique appears to have broad applications in optics and electron optics, in vacuum technology and in the encapsulation and mounting of electronic components.

\section{DESCRIPTION OF GLASS-METAL SEALING METHOD}

The sealing method has been applied to glass-metal, glass-semiconductor and, more recently, to glassglass systems. In this section the first two, operationally identical cases are discussed using as an example a seal of an iron-nickel-cobalt alloy such as Kovar to a matching glass such as Corning \#7052 or $\# 7056 .^{2}$ The faces that are to be sealed are first lapped and polished so that they are both flat and smooth. After a thorough clean-up, they are placed on top of each other and heated to a temperature that is typically in the range $400^{\circ} \mathrm{C}$ to $550^{\circ} \mathrm{C}$. A dc voltage of about $1000 \mathrm{~V}$ is then applied between the alloy and the glass such that the glass is at a negative potential with respect to the alloy. If this voltage is maintained for more than a few seconds one finds that the glass and the alloy form a strong hermetic bond.

One of the important process parameters is temperature. In general, sealing at the annealing temperature of the glass gives good results. In some special cases much lower bonding temperatures are practical. For instance the annealing temperature of Corning $\# 7052$ is $480^{\circ} \mathrm{C}$, yet good Kovar $\# 7052$ seals have been made at $350^{\circ} \mathrm{C}$. Similarly, though the annealing point of Pyrex $\# 7740$ is $565^{\circ} \mathrm{C}$, seals of Pyrex to silicon are feasible at a temperature as low as $300^{\circ} \mathrm{C}$.

The voltage is generally in the range 50 to $1000 \mathrm{~V}$ with the optimum value depending on the temperature and the geometry. If the voltage is applied after the parts have reached a steady temperature, it is found that a relatively large initial current decays quite rapidly with time. As discussed below it is sometimes preferable to apply the voltage at a low temperature and maintain it while the parts heat up and dwell at the bonding temperature.

A sealing time of one to five minutes is typical. In general, the sealing time becomes longer as the sealing temperature and voltages are reduced. 
The surface conditions of the parts are crucial. Unless the parts mate very closely and are quite smooth, they will not form strong hermetic bonds. Most sealing has been done with surfaces having a finish of about $1 \mu \mathrm{in}$. rms. Under these conditions no preoxidation of the metal surfaces is required, but usually a very thin oxide layer forms during the sealing operation. In the case of preoxidized Kovar good seals have been found feasible to surfaces that had a roughness of up to $6 \mu$ in. A convenient criterion for the preferred surface mating and surface smoothness is that, when the glass is placed on the metal, the parts should be sufficiently close so as to give rise to interference fringes. Furthermore, with the glass lightly pushed against the metal, no more than 4 or 5 fringes should be visible over a linear distance of $25.4 \mathrm{~mm}$. If the sealing temperature is reduced, the requirement for flatness and smoothness becomes more stringent.

As in conventional glass-metal sealing, it is generally advantageous to select glass and metal parts with closely matching coefficients of thermal expansion. However, when the parts are in the form of thin foils or films, seals to non-matching materials are feasible. Seals have been made in room air and also in various controlled atmospheres such as oxygen, steam, nitrogen, hydrogen, argon and in vacuum.

Many methods are available by which electrical contact can be made to the glass. For small geometries, e.g. $6.5 \mathrm{~mm} \times 6.5 \mathrm{~mm}^{2}$, contacting by the point of a wire is adequate. For larger geometries it is often convenient to make contact by means of metal rings or plates which are placed on the glass. These metal electrodes will not seal to the glass, because they are at a negative potential. In other situations, painted-on electrodes have been used. Contact to glass tubing has been made by wrapping a wire around the tubing.

The process works for a large number of glassmetal systems. A partial list of materials is shown in Table I. In some cases, notably molybdenum, a tendency has been observed for a fairly thick, poorly adhering oxide to form during the bonding process. Though the oxide bonds strongly to the glass, the resulting seal is mechanically weak with failure occurring at the metal-oxide interface. Two procedures have been found to be useful in this case. In one method, the growth of oxide is impeded by the simple expedient of applying the bonding voltage at room temperature and maintaining it while the parts are heated to the bonding temperature. As will become evident later, the voltage generates an electrostatic force which pulls together the metal and glass
TABLE I

Selected materials that have been sealed by the field-assisted process.

\begin{tabular}{ll}
\hline Material & Bonded to glass $^{\mathrm{a}}$ \\
\hline Kovar & 7052 \\
Molybdenum & 7056 \\
Titanium & 7052 \\
Tantalum & 0080 \\
Carpenter 49 & 7052 \\
& Mosaic F/O \\
Niromet 44 & Corning F/O \\
& Mosaic F/O \\
NiSpan & Corning F/O \\
Silicon & 7740 \\
& 7740 \\
Germanium & 7070 \\
Al film on 7740/7052/0120 & 7052 \\
Al film on CerVIT & $7740 / 7052 / 0120$ \\
SiO film on 7740/7056 & CerVIT \\
Si film on quartz & $7740 / 7056$ \\
NiCr film on 7740 & quartz \\
SiO film on silicon & 7740 \\
\hline
\end{tabular}

${ }^{a}$ Numbers refer to Corning glasses.

and obstructs the access of oxygen to the metal surface. Since the mechanism becomes effective at relatively low temperatures at which thermal oxidation is slow, the result is a substantial reduction of oxide thickness. In a different method one deposits on the polished molybdenum surface a metallic film (e.g. aluminium) which is known to bond easily to glass, thus producing a Mo-Al-glass sandwich of quite satisfactory strength.

Though most work has been limited to the sealing of glass to metals and semiconductors, it has been found that field-assisted glass sealing also has applications in the sealing of glass to glass. With some glass to glass systems, bonding is achieved simply by placing the polished faces on top of each other, heating them to the bonding temperature and applying a suitable voltage. ${ }^{3}$ If the two glasses have the same composition, then the polarity is obviously irrelevent. On the other hand, if the glasses have different compositions, the process usually works best if the glass with the higher sodium concentration is at a negative potential.

In another approach, excellent results may be obtained by coating one of the glasses with a thin metal film (e.g. by evaporation or sputtering) and sealing the second glass to the film. This technique has, for instance, been applied to the bonding of fused quartz parts. In this instance, the intermediate film is sputtered silicon and the seal is made at about 
$900^{\circ} \mathrm{C}$ with $1000 \mathrm{~V}$. As usual, the silicon should be at a positive potential; electrical contact can be made either directly to the film or, if more convenient, to the coated quartz but within reasonable vicinity of the film. Seals of this type have been shown to be strong and hermetic. Perhaps somewhat surprisingly, much the same results may also be obtained if a film of silicon monoxide is substituted for the metal film.

Finally, bonds of silicon to silicon have been made by the following two methods. In our laboratory bonding was accomplished by providing the silicon faces with fairly thick films of thermal oxide and then using an electric field to seal the two oxide films to each other, thus producing a sandwich of siliconsilicon dioxide-silicon. ${ }^{4}$ At the Research Triangle Institute, Brooks, Donovan and Hardesty ${ }^{5}$ coated one of the silicon surfaces with a glass layer to which they bonded the second silicon surface. Their method undoubtedly is applicable to other semiconductors and metals.

\section{SEAL PROPERTIES}

The strength of seals has been investigated in considerable detail for the system Kovar \#7052 glass. $^{2}$ A distribution of tensile strength is shown in Figure 1. All seals were fabricated from non-preoxidized Kovar parts with a surface finish of less than $1 \mu$ in. which were bonded to discs of optically polished \#7052 glass at $500^{\circ} \mathrm{C}$ with $1000 \mathrm{~V}$ applied for 10 minutes. The figure shows that $80 \%$ of the seals broke in the range $1500-3000 \mathrm{psi}$. The preponderant failure mechanism was fracture of the glass in a region closely adjacent to the glass-Kovar interface. Less frequently, failure occurred either within the oxide or at the alloy-oxide interface. Occasionally, failure was observed at the glass-oxide interface.

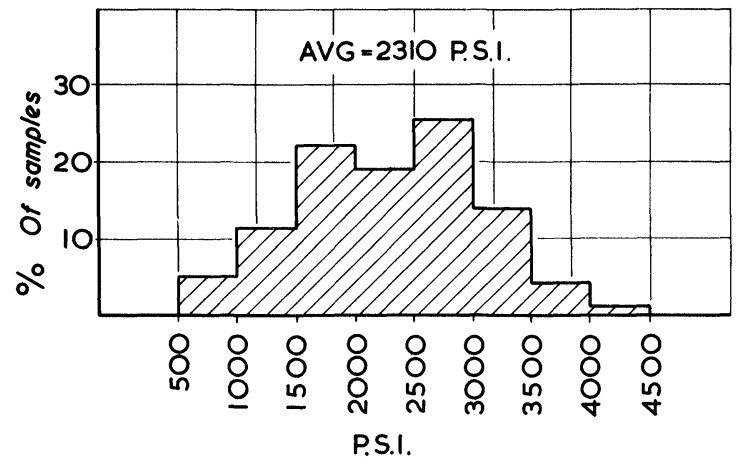

FIGURE 1 Tensile strength distribution of Kovar \#7052 bonds.

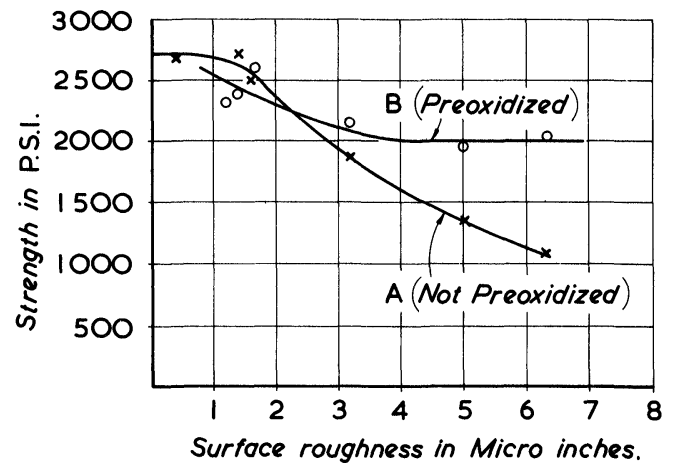

FIGURE 2 Effect of surface roughness on tensile strength of Kovar \#7052 bonds.

As a follow-up to the above experiments, the effect of surface roughness on seal strength was investigated. The results, shown in Curve A of Figure 2 , indicate an unmistakable reduction in strength with increasing surface roughness. Concurrently, the yield of hermetic seals dropped sharply, and the failure mechanism shifted from glass fracture for the smoothest samples to failure at the interface for samples with a surface roughness of greater than $1.5 \mu$ in. (see Curve A, Figure 3). Rather surprisingly, the results were quite different when the alloy was preoxidized by exposing it to air at $350^{\circ} \mathrm{C}$ for 15 minutes (oxide thickness of about $1000 \AA$ ). As shown in Curve B, Figure 2, the dependence of seal strength on surface finish becomes much weaker in the range 1 to $6 \mu$ in. rms. Hermeticity could be obtained consistently, and failure occurred in the glass (Curve B, Figure 3) throughout the range.

For purposes of our work, a seal was defined to be hermetic if no leakage was indicated on the most

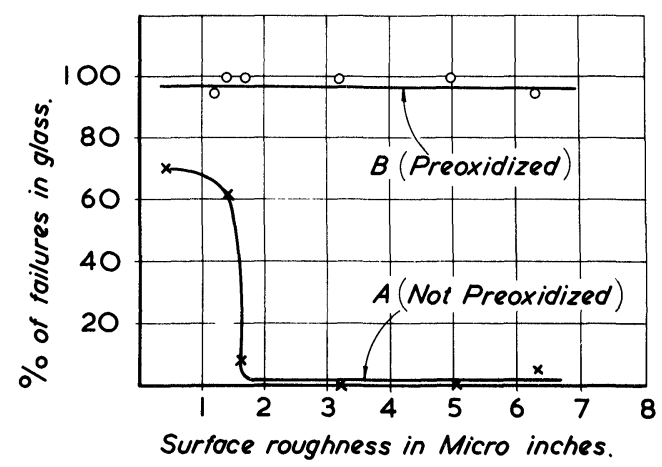

FIGURE 3 Effect of surface roughness on failure mode of Kovar \# 7052 bonds. 
sensitive scale of a Helium Leak Detector $\dagger$, i.e. if possible leakage was less than $5 \times 10^{-10} \mathrm{cc} \mathrm{He} / \mathrm{sec}$. On this basis a large number of glass-metal systems were capable of producing hermetic seals, such as silicon to \#7740 glass, fiberoptics to Niromet alloy, and \#7052 glass to Kovar alloy. In the latter case, special tests were also made which assured a leak rate of less than $10^{-13} \mathrm{cc} \mathrm{He} / \mathrm{sec} . \dagger$

As previously stated, the field-assisted sealing technique produces strong, hermetic bonds without macro-distortion in the glass and should therefore be useful in the assembly of optical components. An application to the sealing of Laser Brewster windows has been recently described by Bernard Smith ${ }^{6}$ who essentially used the procedure outlined in Sec. 2 to bond elliptic quartz windows to a quartz system while maintaining the Brewster angle within the required degree of accuracy.

The stability of the seals was assured by the following tests:

1) As described ${ }^{2}$, Kovar \#7052 seals, fabricated at $400^{\circ} \mathrm{C}$ in air, were heated to $700^{\circ} \mathrm{C}$ for 30 minutes in atmospheres of air, nitrogen and forming gas. It was suspected that such treatments might produce diffusion of the respective gases into the interface region of a seal, followed by reaction of the gases with the thin oxide layer which invariably forms under the above sealing conditions. If this were to occur, it might affect the strength of the seals in accordance with the predictions of various glass sealing theories. ${ }^{7,8}$ In practice, the above heat treatments produced no visible evidence that the oxide under the seal had changed. In tensile tests the heat-treated seals had the same strength as seals without heat-treatment and, as usual, the treated seals failed in the glass.

2) Subsequent to the application of the bonding voltage, and while still at the bonding temperature, a dc voltage of opposite polarity (metal negative) was applied to test whether the bond had any reversible features. ${ }^{9}$ Using tensile bond strength as the criterion, no effect was detected.

3) Thermal cycling and thermal shock tests were performed on seals of fiber optics face plates of

\footnotetext{
†Veeco Helium Leak Detector MS-9, Veeco Instrument Inc., Plainview, N.Y.

$\dagger$ This estimate was derived from the characteristics of a photo cathode in a vacuum tube which contained a field assisted bond. After the tube was evacuated, it was sealed off and its cathode emission was monitored over a period of several months.
}

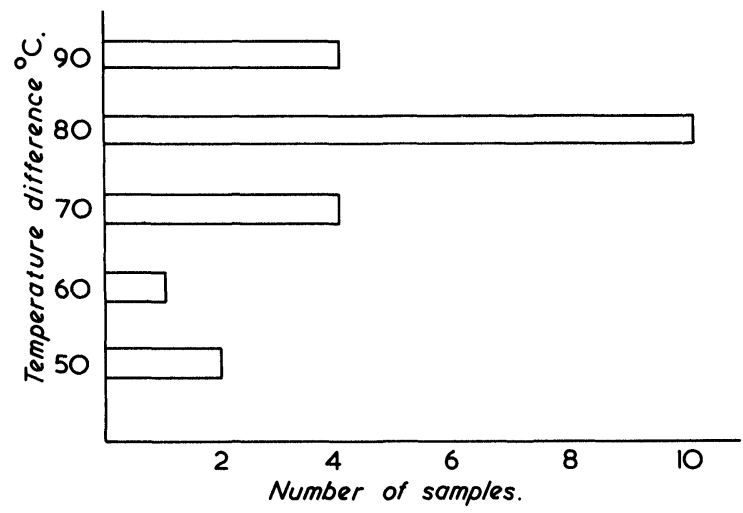

FIGURE 4 Distribution of failures of Kovar \#7052 bonds during thermal shock test.

$25.4 \mathrm{~mm}$ diameter to flanges of Niromet 44 alloy. The thermal cycling consisted of five cycles at alternately $125^{\circ} \mathrm{C}$ and $-25^{\circ} \mathrm{C}$, and had no detectable effect on the seals. More instructive was a destructive thermal shock test in which seals were rapidly transferred from hot to cold water. The temperature difference between the two water baths was increased in $10^{\circ} \mathrm{C}$ steps until a seal cracked or started to leak. Figure 4 shows a distribution of failures at their respective temperature differentials. This distribution is quite similar to what is found for conventional frit seals of similar geometry.

In summary, all testing to date has indicated that properly designed field assisted seals are irreversible and stable and that their mechanical and thermal properties are similar to those of conventional seals of the same geometry.

\section{THEORY}

A considerable amount of work has been carried out at this Laboratory to try and clarify the rôle of the applied voltage during the bonding process. ${ }^{1,10}$. It has been established that one function of the field is as follows: When the glass and the metal parts are placed on top of each other, they contact at only a few points. Over most of their overlapping area they are separated by a gap which has a width of about $1 \mu$. This gap results in interference fringes which are readily observed. Before any bond formation can take place, the parts must be brought into intimate physical contact over their whole sealing area. This is accomplished by the applied voltage which sets up an electrostatic field in the gap. The latter, in turn, generates an attractive force that pulls the parts 
together, and holds them together under considerable pressure.

Since the initial gap between glass and metal is generally quite non-uniform, so also is the electrostatic force. As a result the parts are usually not pulled into physical contact instantaneously over the whole area; typically, contacting starts at a single point and then gradually spreads over the remaining area. This is believed to be advantageous in that it tends to prevent the formation of air pockets.

It should be stressed that the above mechanism would require extremely high voltages at low temperatures when the glass resembles an insulator since most of the applied voltage would drop across the glass rather than the gap. However, at elevated temperatures most glasses behave like electrolytes. ${ }^{11}$ In many glasses the mobile species are positive ions, frequently $\mathrm{Na}^{+}$derived from the dissociation of $\mathrm{Na}_{2} \mathrm{O}$. A voltage of $500 \mathrm{~V}$, applied under these conditions, deploys almost entirely across the gap between glass and metal. With a gap width of about one micron, electric fields of the order of $5 \times 10^{6} \mathrm{~V} / \mathrm{cm}$ could be expected.

Although the temperature may be sufficiently high for the generation of electrostatic attraction, it may not be high enough for rapid bond formation. Nevertheless, as noted before, application of the field at a low temperature may be desirable to impede oxidation of the metal.

After the glass and the metal are brought into contact, charge begins to pass through the glass. With the metal to be bonded having a positive polarity, sodium ions in the glass will migrate toward the negative electrode. Plated out sodium was first reported in field assisted bonds by $\mathrm{DeNee}^{12}$ who also pointed out that the free sodium can combine with adsorbed moisture on the glass to form $\mathrm{NaOH}$. The latter will react with the glass and form sodium silicate and water.

From electrostatic considerations it may be demonstrated that for each $\mathrm{Na}^{+}$ion that is plated out at the cathode, a corresponding $\mathrm{Na}^{+}$ion is removed from a thin glass layer adjacent to the anode (metal to be bonded). At first sight, one might expect that this would produce a large charge imbalance which should give rise to enormous electric fields and result eventually in dielectric breakdown. This, however, is not what is usually observed. The following cases may be differentiated:

1) Metal ions from the anode are pulled into the glass. If their mobility is comparable to that of the sodium ions, they simply replace the latter. Under these conditions, the electric field at the interface will not be greatly different from the field in the bulk of the glass, and the anodic metal surface, no longer strongly attracted, will tend to separate from the glass. This case has been observed in the silver-Pyrex system. ${ }^{10}$ No bonding could be achieved in this situation.

2) Metal ions from the anode enter the glass as in (1). However, in this case their mobility is orders of magnitude lower than that of sodium so that fields of about $10^{6} \mathrm{~V} / \mathrm{cm}$ remain at the glass-metal interface. The high field region which typically has a width of the order of microns is essentially free of sodium ions. Most of the vacant sodium sites become occupied by the foreign metal ions and the net space charge remains relatively small. Hence, the field remains below its breakdown value. This mechanism has been identified in the aluminum-Pyrex system by means of electrical and electron microprobe measurements, ${ }^{10}$ and it is conducive to bond formation.

A somewhat similar case has been observed by Borom $^{13}$ in an iron-sodium disilicate system. Electron microprobe examination clearly showed that iron replaced sodium in the glass boundary layer. However, in this case only a small percentage of the sodium was removed from the high field region.

3) Under the influence of the high field, oxygen ions in the glass drift toward the anode and chemically combine with the metal. Experiments carried out in a reducing atmosphere demonstrated that in the Kovar \#7052 system oxidation occurred under the bonding glass which covered a part of a Kovar disc. However, where the Kovar was not covered by glass it remained free of oxide. ${ }^{10}$ Similar results were also reported by Borom. ${ }^{13}$

4) Other mechanisms could be envisioned. For instance, DeNee ${ }^{12}$ suggested that adsorbed water could dissociate permitting hydrogen ions to replace the migrating sodium ions while the hydroxyl ions might react with the metal.

In the presence of a high field region, as in cases 2 , 3 and possibly 4 , the current flow is expected to be proportional not to the applied voltage but rather to the exponential of the field. Thus a semilog plot of current versus field for the aluminum-Pyrex system was found to be a straight line (see Figure 5 and consult Ref. 10 as to how the magnitude of the field was measured).

For a given applied voltage, the field is inversely proportional to the width of the boundary region 


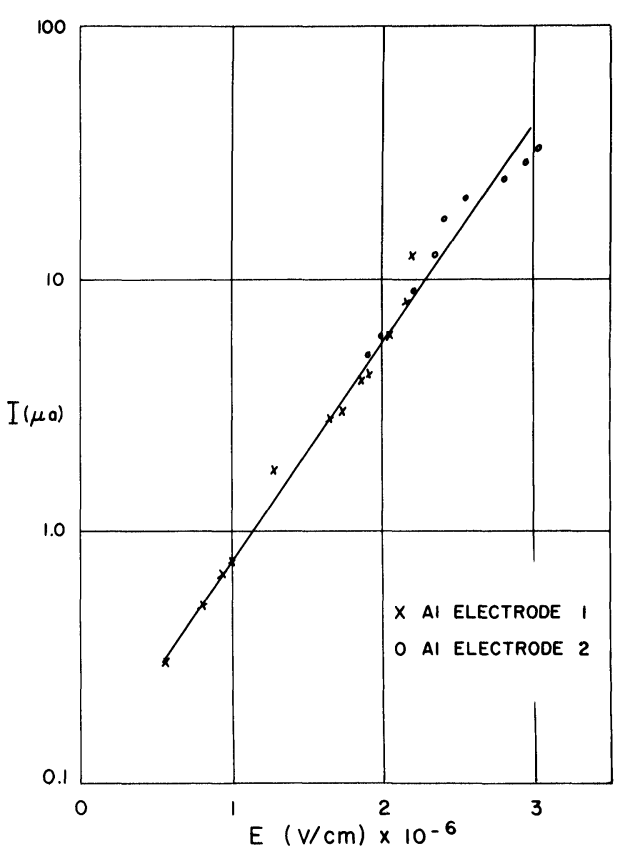

FIGURE 5 Semilog plot of current versus field for Al--Pyrex system.

from which the mobile $\mathrm{Na}^{+}$ions have been removed. Initially, the depleted region is very thin and the resulting field, and hence, the current is large. As more $\mathrm{Na}^{+}$ions are being removed, the depleted region becomes increasingly wide so that there is a steady drop in current with time. This is illustrated in Figure 6 which shows the decay of current over an extended time period for the aluminum-Pyrex system.

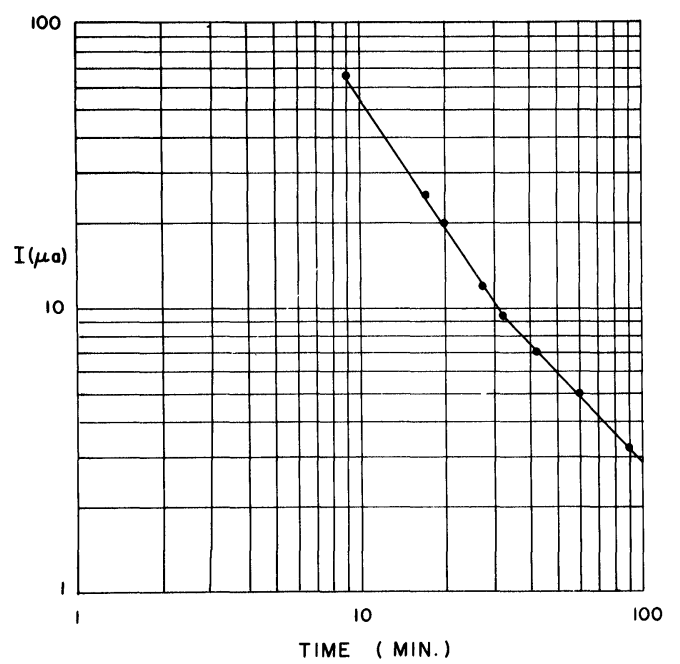

FIGURE 6 Plot of current versus time for Al-Pyrex system.
While the general features of Figures 5 and 6 are quite reproducible, the exact shape usually becomes modified during the initial part of a bonding operation because, as mentioned earlier, the parts do not come into contact instantaneously over the whole area. Thus, the initial current flow is frequently quite non-uniform.

While there is no doubt that ion migration takes place during field assisted bonding, it remains to be seen whether it is instrumental in establishing the bond or whether it is merely incidental to it. In this connection it is interesting to note that in some of the most influential theories on glass-metal sealing, ${ }^{7,8}$ it is postulated that a satisfactory bond requires the structure: metal-metal oxide-glass boundary layer saturated with metal oxide-bulk glass. In conventional seals, the glass is liquid during bonding so that it can attain metal oxide concentrations close to saturation at the liquidus. This feature is considered to be essential for the formation of strong bonds. Bonds made by the field assisted process evidently have a similar structure. However, the concentration of metal oxide is determined by the initial sodium concentration in the glass since only ion exchange appears to be involved. As a result, the concentration is generally much lower than the equilibrium concentration at the liquidus of the glass.

As stated above, large electric fields exist in the glass during the bonding process and are responsible both for the electrostatic attraction of glass and metal and for the ion migration in the glass. It has sometimes been suggested that the fields persist after a seal is cooled to room temperature, and by electrostatic attraction contribute to the bond strength. This speculation is not borne out by experiments, which indicate that the fields dissipate rapidly during cooling. In any case, the electrostatic attraction could only make a very minor contribution to bond strength since its magnitude under optimum conditions was measured to be only of the order of $350 \mathrm{psi}^{10}$ as compared to the strength of 2000 to 3000 psi for a typical glass-metal seal.

\section{APPLICATION TO SILICON STRAIN GAUGES}

Although the bonding technique appears to have broad applications in several fields, ${ }^{9}$ this section will concentrate on its application to the mounting of silicon strain gauges because this area has been researched most extensively and published data are available. 
Conventionally, silicon strain gauges are mounted to the structural elements by means of adhesives such as the various expoxies. In some commercially available gauges the epoxy has been replaced by a glass frit which is far superior to the former in that mechanical creep is greatly reduced and the temperature capabilities of the bond are significantly increased. A further improvement in mounting technique can be achieved by the substitution of a glass plate for the glass frit. The plate, typically $20 \mu$ thick, is bonded by means of the field assisted technology to form an intermediate layer between the strain gauge and the structural member. The glass plate inherently possesses the same advantages as the frit but, in addition, is preferable in the following respects:

1) Glass frits which can be bonded at a relatively low temperature, e.g. $300^{\circ} \mathrm{C}$ to $350^{\circ} \mathrm{C}$, usually fail to match the silicon with regard to thermal expansion. By contrast, field-assisted sealing permits the selection of glasses that match silicon extremely closely.

2) Jigging and fixturing is easier, and alignment more accurate, if no liquid phase is present.

3) Provided the surfaces are smooth and clean, very uniform and reliable bonds, free of bubbles, are obtainable by the field assisted technique.

Preliminary experiments in our laboratory indicated that good results could be obtained provided the three materials - silicon, glass, and substrate had closely matched coefficients of thermal expansion. The same approach could probably be applied also to metallic foil gauges.

In another approach which is particularly suitable to fluid pressure sensors, the strain gauge is an integral member of a silicon diaphragm which is bonded to a silicon mount. An obvious virtue of this scheme is the fact that the diaphragm and the mount are of the same material and thus constitute a perfect thermal match. However, this advantage is sometimes obviated by the use of epoxies as the bonding agent. With the use of field assisted bonding several superior options are available. In an extension of the previously described approach, a thin glass plate can serve as the "cement" between the silicon parts. An interesting variation on this scheme has been described by Brooks, Donovan and Hardesty. ${ }^{5}$ Instead of a glass plate, they employ a deposited glass film. The film consists of Corning \#7740 ("Pyrex") borosilicate glass which is rf sputtered onto one of the silicon parts to a thickness of at least $4 \mu$. After deposition, the films are annealed, preferably in an ambient of steam, in the range $500^{\circ} \mathrm{C}$ to $900^{\circ} \mathrm{C}$. Finally, a silicon diaphragm is placed on the coated substrate and bonded by the field assisted process in the temperature range $450^{\circ} \mathrm{C}$ to $550^{\circ} \mathrm{C}$ with the coated part being at a negative potential. An unusual feature of the process is that the dc voltage is applied in steps as the current decreases with time. A maximum voltage of $50 \mathrm{~V}$ was found to produce satisfactory hermetic seals.

In yet another variation of this general approach the "cement" between the silicon parts is $\mathrm{SiO}_{2}$ rather than Pyrex. An advantage of $\mathrm{SiO}_{2}$ is a far higher temperature capability and perhaps an even greater absence of creep than in Pyrex. A disadvantage is the marked mismatch in thermal expansion (about $30 \times 10^{-7} \mathrm{~cm} / \mathrm{cm},{ }^{\circ} \mathrm{C}$ for silicon as compared to $5 \times 10^{-7} \mathrm{~cm} / \mathrm{cm},{ }^{\circ} \mathrm{C}$ for $\left.\mathrm{SiO}_{2}\right)$. A brief description of the $\mathrm{Si}-\mathrm{SiO}_{2}-\mathrm{Si}$ bonding method follows. ${ }^{4}$ The carefully polished silicon faces that are to be bonded are first provided with an oxide layer having a thickness in the range 1.5 to $2.5 \mu$. In our laboratory this was accomplished by conventional thermal oxidation at $1200^{\circ} \mathrm{C}$ in an atmosphere of wet oxygen. Presumably, the deposition of an oxide could also be achieved by pyrolytic methods or by sputtering. Whatever the method of deposition, it appears to be important that the oxide layers are as perfect and pure as possible so that they can, without dielectric breakdown, support the large electric fields at high temperatures that are required for successful bonding.

After oxide deposition the silicon parts are placed against each other, with the oxide coated faces in contact, and heated to a temperature of about $900^{\circ} \mathrm{C}$. A voltage is then applied between the parts for 5 to 10 minutes. The procedure differs from the glassmetal sealing process in two respects.

1) In virtue of the symmetry of the situation there is no preferred polarity.

2) While the magnitude of the applied voltage can vary over a wide range in glass-metal sealing, it is critical in the bonding of the thin oxide layers, its preferred value depending primarily on the thickness of the layers and the perfection of the oxide. For oxide layers that were $1.5 \mu$ thick, a voltage in the neighborhood of 150 volts was found to be appropriate. If the two oxide films acted as perfect insulators the resulting electrostatic field would amount to only $5 \times 10^{5} \mathrm{~V} / \mathrm{cm}$ and could be expected to be an order of magnitude lower than the breakdown field. Nevertheless, breakdown sometimes occurs under these conditions, especially if the 
TABLE II

\begin{tabular}{|c|c|c|c|c|}
\hline Bond & $\begin{array}{l}\text { Zero shift with } \\
\text { temp. }\left(\% / 38^{\circ} \mathrm{C}\right)\end{array}$ & $\begin{array}{l}\text { "Span" output } \\
\text { shift with temp. } \\
\left(\% / 38^{\circ} \mathrm{C}\right)\end{array}$ & $\begin{array}{l}\text { Compensated } \\
\text { "span" output } \\
(\mathrm{mV} / \mathrm{V})\end{array}$ & $\begin{array}{l}\text { Compensated } \\
\text { zero pressure } \\
\text { output }(\mathrm{mV} / \mathrm{V})\end{array}$ \\
\hline Field-assisted & $\begin{array}{l}-.098\left(+100^{\circ} \mathrm{C}\right) \\
-.140\left(-40^{\circ} \mathrm{C}\right) \\
\mathrm{W} / \mathrm{C}^{\mathrm{a}} \\
+.52\left(+100^{\circ} \mathrm{C}\right) \\
-.73\left(-40^{\circ} \mathrm{C}\right) \\
\mathrm{N} / \mathrm{C}^{\mathrm{a}}\end{array}$ & $\begin{array}{l}-.18(900 \mathrm{psi}) \\
-.20 \\
\mathrm{~W} / \mathrm{C}^{\mathrm{a}} \\
+.09(40 \mathrm{psi}) \\
+.08 \\
\mathrm{~W} / \mathrm{C}\end{array}$ & 12.9 & .42 \\
\hline Epoxy & $\begin{array}{l}+.78 \\
\mathrm{~W} / \mathrm{C}\end{array}$ & $\begin{array}{l} \pm .12(300 \mathrm{psi}) \\
\text { W/C }\end{array}$ & 12.7 & 13.5 \\
\hline
\end{tabular}

${ }^{\mathrm{a}} \mathrm{W} / \mathrm{C}=$ with compensation $\mathrm{N} / \mathrm{C}=$ no compensation.

voltage is applied for an excessively long time. Thus, careful empirical definition of the bonding conditions is required if good yields are to be attained. $\dagger$

To date, no performance data have been published for strain gauges that were assembled by the above techniques. However, some data are available for yet another mounting scheme which has been thoroughly explored by Orth and Cannon. ${ }^{14}$ Again, the sensing elements are piezoelectric resistors diffused into a silicon diaphragm (Yerman integral silicon transducer ${ }^{15}$ ). For purposes of comparison, the diaphragms were attached to the polished ends of \#7740 Pyrex glass tubes which served as primary mounts using either epoxy or the field assisted bonding process. In the latter case specially designed fixtures were utilized to maintain the required geometry in a horizontal tube furnace. Bonding was accomplished at a voltage of $1 \mathrm{kV}$ and at relatively low temperatures. The devices were tested as fluid pressure sensors. The data in Table II is taken from the paper by Orth and Cannon and compares epoxy mounted transducers with those bonded by the field assisted process.

In addition, the paper presents data on hysteresis and on response to extended static and cyclic load. Transducers mounted by means of epoxy on Invar

$\dagger$ This method of sealing silicon to silicon has also interesting applications in other areas. For instance, procedures are available by means of which it is possible to thin down one of the silicon layers to almost any desired value. As a result one obtains a thin silicon film on an insulating layer $\left(\mathrm{SiO}_{2}\right)$ which in turn is backed by a thick silicon wafer. ${ }^{4}$ Functionally, this structure is similar to the SOS structure (pyrolytically deposited silicon film on sapphire) which is finding increasing acceptance in the manufacture of MOS circuitry. However, since the silicon layer in the former structure consists of bulk material it usually has superior electrical qualities as compared to the deposited film. typically had hysteresis of $0.1 \%$ of full scale output at 300 psi. The corresponding average value for diaphragms mounted by the field assisted technique was $0.022 \%$ with a standard deviation of 0.030 . No bond failures were observed when 4 samples were subjected to a static load of 1000 psi for 1000 hours and 6 samples were cyclically loaded $\left(10^{5}\right.$ cycles in 500 hours). The authors conclude that field assisted bonding of silicon strain gauges removes the uncertainties inherent in epoxy bonds and can be used in the manufacture of simple measurement devices which have unusually good characteristics especially with regard to hysteresis, sensitivity and temperature compensation.

\section{CONCLUSIONS}

Field assisted glass sealing offers a simple and rapid method of making reliable, strong hermetic bonds at unusually low temperatures. Of all process variables, only surface flatness and surface smoothness are critical.

Apparently, the technique is applicable only if the following conditions are met:

1) At least one of the parts that are to be bonded to each other should act as an essentially solid electrolyte at the bonding temperature.

2) Under the influence of the applied dc voltage, a high electrostatic field should be set up at the interface of the electrolyte and the second part. This is equivalent to the requirement that the boundary region should be depleted of mobile ions.

3) Unless one of the parts is extremely thin and malleable, the materials must have reasonably matching thermal expansion to avoid cracking. 
In principle, the technique might be expected to work also if an insulator is substituted for the solid electrolyte. However, in practice we have not, so far, encountered a material which behaved as a true insulator at the temperature at which bonding was feasible.

It is probable that as a result of the high field at the interface ions from one part migrate into the other. In a few cases, such an exchange has been documented experimentally. It remains to be investigated whether the ion migration is instrumental in the establishment of a low temperature bond or whether it is merely incidental to it.

In the discussion of applications, this paper limited itself primarily to the very successful mounting of silicon strain gauges. This area had received much attention presumably because of a clearly perceived need for technical improvement and perhaps also because the technique could be applied in a perfectly straightforward manner. However, it is felt that field assisted glass sealing has broad applications in fields as diverse as optics, vacuum technology and electronics.

\section{REFERENCES}

1. D. I. Pomerantz, U.S. Patent No. 3397 278. G. Wallis and D. I. Pomerantz, J. Appl. Phys., 40, 3946 (1969).

2. G. Wallis, J. Dorsey and J. Beckett, Am. Ceram. Soc. Bull. 50, (12) 948 (1971).

3. S. Wolsky, G. Wallis, D. Pomerantz and J. Dorsey, U.S. Patent No. 3589965

4. G. Wallis, Paper 239 RNP presented at Electrochem. Soc. Meeting, Atlantic City, Oct. 4-8, 1970

5. A. D. Brooks, R. P. Donovan and C. A. Hardesty, J. Electrochem. Soc. 119 (4), 545 (1972).

6. B. Smith, IEEE J. Quantum Electron, 9, 546 (1973)

7. J. A. Pask and R. M. Fulrath, J. Am. Ceram. Soc. 45, 592 (1962).

8. B. W. King, H. P. Tripp and W. H. Duckworth, J. Am. Ceram. Soc. 42, 504 (1959).

9. G. Wallis, J. Automot. Eng. 79, 15 (1971).

10. G. Wallis, J. Am. Ceram. Soc. 53, 563 (1970).

11. W. A. Weyl and E.C. Marboe, The Constitution of Glasses, vol. II, pt. 2, (John Wiley and Sons, Inc. New York, 1967) p. 893.

12. P. B. DeNee, J. Appl. Phys. 40, 5396 (1969).

13. M. P. Borom, J. Am. Ceram. Soc. 56, 254 (1973).

14. E. D. Orth and P. Cannon, Secretariat Range Commanders Council, White Sands Missile Range, N. M., Seventh Transducer Workshop, 4-6 April 1972, p. 119.

15. A. J. Yerman, U.S. Patent No. 3537319. 

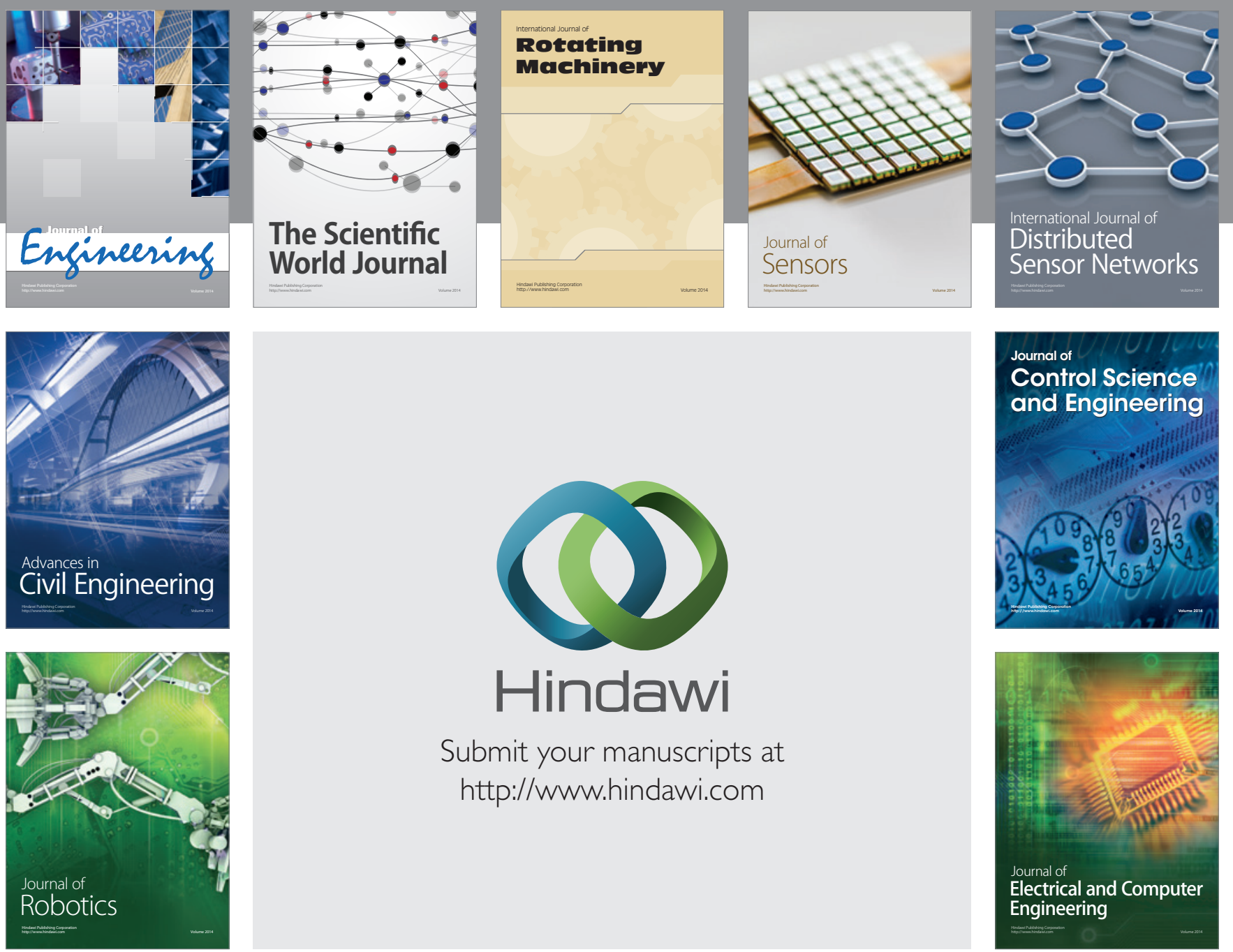

Submit your manuscripts at

http://www.hindawi.com
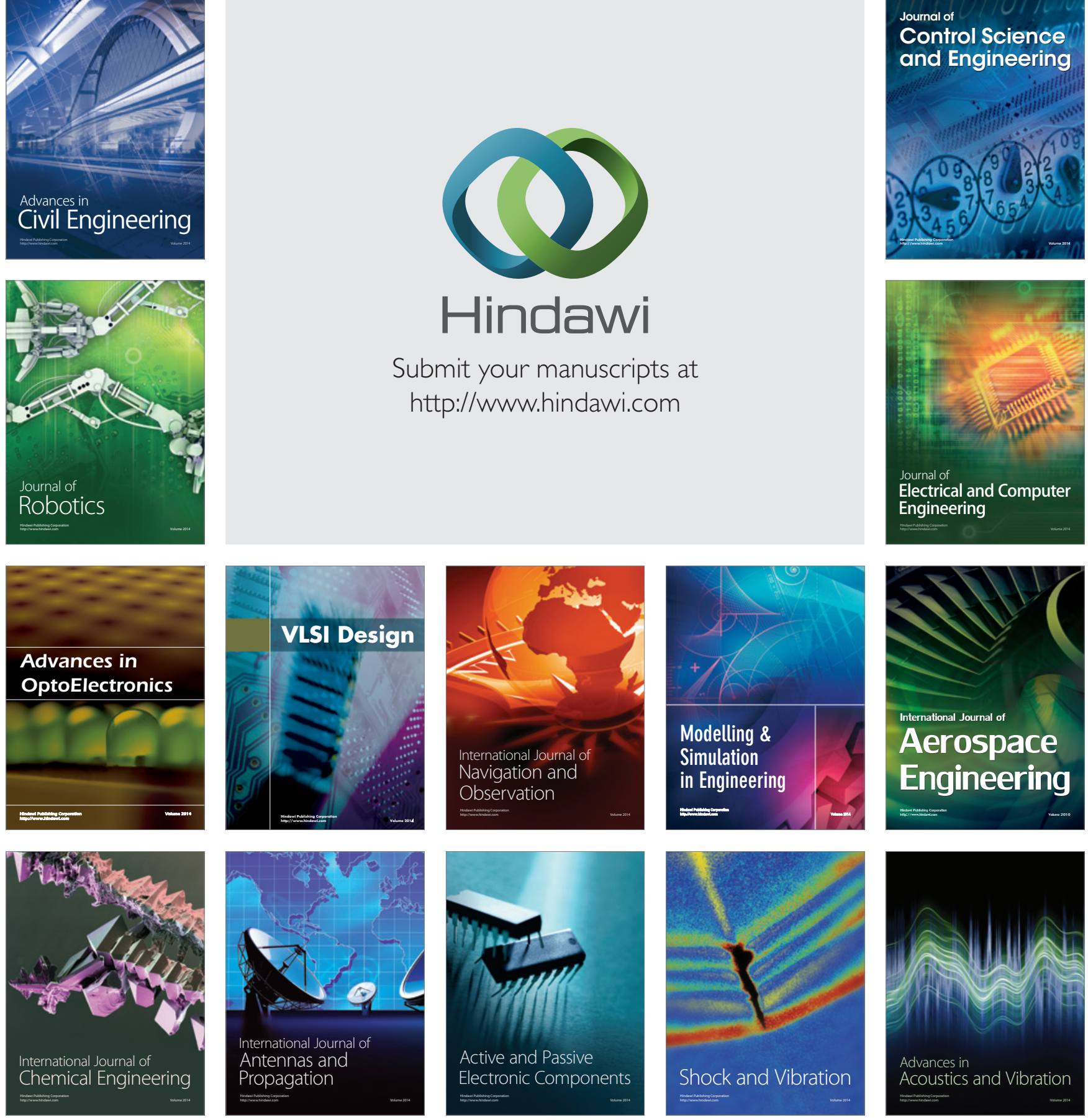